\title{
Side-Chain Crystallization of a New Comb-Like Polymer Prepared from Isopropenyl-Triazine Having Two Octadecanoyl Groups
}

\author{
Yasuo Yuki, Hideo Kunisada, and Yuichi MiYaKe \\ Department of Materials Science and Engineering, Nagoya Institute of Technology, \\ Gokiso-cho, Showa-ku, Nagoya 466 Japan
}

(Received November 1, 1990)

\begin{abstract}
New isopropenyl-1,3,5-triazine having two long acyl groups, that is, 2,4bis[p-(octadecanoylamino)anilino]-6-isopropenyl-1,3,5-triazine (BSIT), was synthesized from reaction of 2,4-bis ( $p$-aminoanilino)-6-isopropenyl-1,3,5-triazine with octadecanoyl chloride. BSIT was polymerized and copolymerized with methyl methacrylate or styrene $\left(M_{1}\right)$ in dimethylacetamide using AIBN as an initiator. Side-chain crystallizations of the resulting homopolymer and copolymers were investigated by a DSC thermogram and X-ray diffractogram. The crystallites of the side-chains melted at $70^{\circ} \mathrm{C}$, below the glass transition temperature of the main chain. There were tight and loose crystallites, and the formation of these crystallites depended on the annealing conditions of the polymers.
\end{abstract}

KEY WORDS Comb-Like Polymer / Isopropenyl-1,3,5-Triazine / Long
Alkyl Group / Side-Chain Crystallization / Copolymerization / Glass
Transition Temperature / Thermal History /

Polymers having long alkyl groups in their side chains, so-called comb-like polymers, have attracted much attention due to specific properties such as side-chain crystallization, ${ }^{1}$ peculiar mechanical properties, ${ }^{2,3}$ ability of liquid crystal formation, ${ }^{4-6}$ and formation of Langmuir-Blodgett film. ${ }^{7}$ In general, the glass transition temperatures $\left(T_{\mathrm{g}}\right)$ of conventional comb-like polymers ${ }^{8}$ are low and the melting temperatures of their side-chain crystallites are higher than their $T_{\mathrm{g}} \mathrm{s} .{ }^{1}$ For example, $T_{\mathrm{g}}$ of poly(octadecyl methacrylate) was estimated in the vicinity of $-100^{\circ} \mathrm{C}, 9,10$ and the melting and freezing temperatures of its side-chain crystallites were $34^{\circ} \mathrm{C}^{11}$ and $23^{\circ} \mathrm{C},{ }^{8}$ respectively. Therefore, one of the major problems for the application of conventional comb-like polymers is that they become rubbery after the melting of their side-chain crystallites. The polymers containing triazine rings have high $T_{\mathrm{g}}$ among vinyl polymers. ${ }^{12,13}$ In previous papers of this series, we investigated the properties of several comb-like polymers containing triazine ring and one long alkyl group in the repeating unit using 2-amino4-[ $p$-octadecyloxyanilino-,${ }^{14} p$-(octadecanoylamino)anilino-(A18IT) ${ }^{15}$ and $N$-octadecylanilino ${ }^{16}$ ]-6-isopropenyl-1,3,5-triazines as monomers. These comb-like polymers showed high $T_{\mathrm{g}} \mathrm{s}$. However, the melting temperatures of side-chain crystallites were below room temperature and their crystallinities were lower than those of conventional comb-like polymers. The glassy state of the main-chain prevents side-chain crystallization.

This paper describes the synthesis and properties of new comb-like polymers having two long acyl groups in the repeating unit using

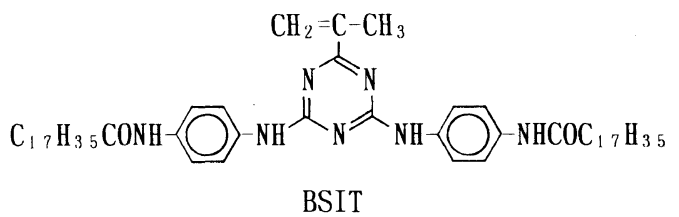


2,4-bis[ $p$-(octadecanoylamino)anilino]-6-isopropenyl-1,3,5-triazine (BSIT) as a monomer.

\section{EXPERIMENTAL AND RESULTS}

\section{Material and Monomer}

Starting material, 2,4-bis( $p$-aminoanilino)6-isopropenyl-1,3,5-triazine (BHIT), was prepared from the reduction of 2,4-bis( $p$-nitroanilino)-6-isopropenyl-1,3,5-triazine by the literature method. ${ }^{17} \mathrm{mp} 176^{\circ} \mathrm{C}$ (lit. ${ }^{17} 176^{\circ} \mathrm{C}$ ).

BSIT was prepared by acylation of BHIT with octadecanoyl chloride as follows. Octadecanoyl chloride $(30.5 \mathrm{~g}, 0.10 \mathrm{~mol})$ was added dropwise to a stirred solution of BHIT $(16.8 \mathrm{~g}$, $0.05 \mathrm{~mol})$ and triethylamine $(11 \mathrm{~g}, 0.10 \mathrm{~mol})$ in $300 \mathrm{ml}$ of dimethylacetamide (DMA) at $0-5^{\circ} \mathrm{C}$. The reaction mixture was filtered after $3 \mathrm{~h}$ of stirring, and the filtrate was poured into water. The precipitate was separated and washed thoroughly with hot water and then with $n$-hexane. Recrystallization from dioxane gave $35.3 \mathrm{~g}$ (Yield $81.0 \%$ ) of BSIT. $\mathrm{mp} 91^{\circ} \mathrm{C}$ and $220^{\circ} \mathrm{C} .{ }^{1} \mathrm{H}$ NMR $\left(\mathrm{D}_{2} \mathrm{SO}_{4}\right) \delta(\mathrm{ppm}): 0.44$ $\left(6 \mathrm{H}, \mathrm{t}, 2 \mathrm{CH}_{3}\right), 0.84\left(60 \mathrm{H}, \mathrm{m}, 2\left(\mathrm{CH}_{2}\right)_{15}\right), 1.40$ $\left(4 \mathrm{H}, \mathrm{t}, 2 \mathrm{CH}_{2}\right), 1.90\left(3 \mathrm{H}, \mathrm{s}, \mathrm{CH}_{3}\right), 6.26(1 \mathrm{H}, \mathrm{s}$, $=\mathrm{CH}), 6.44(1 \mathrm{H}, \mathrm{s},=\mathrm{CH})$. Anal. Found: $\mathrm{C}$, $74.68 \% ; \mathrm{H}, 10.28 \%$; N $11.22 \%$. Calcd for $\mathrm{C}_{54} \mathrm{H}_{87} \mathrm{~N}_{7} \mathrm{O}_{2}: \mathrm{C}, 74.87 \% ; \mathrm{H}, 10.12 \% ; \mathrm{N}$, $11.32 \%$

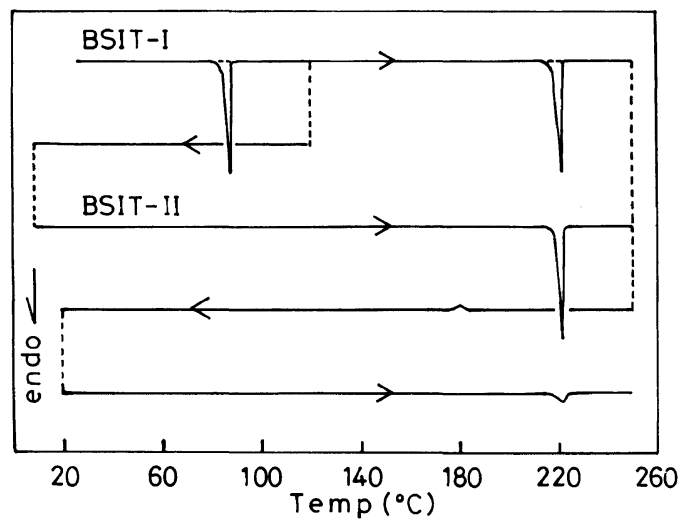

Figure 1. DSC thermograms of BSIT recrystallized from dioxane-water mixture and annealed BSIT at a heating rate of $10^{\circ} \mathrm{C} \mathrm{min}^{-1}$ and a cooling rate of $2^{\circ} \mathrm{C} \mathrm{min}^{-1}$.
BSIT was soluble in THF, $m$-cresol, pyridine, DMF, DMA, and $\mathrm{H}_{2} \mathrm{SO}_{4}$, but insoluble in DMSO and common organic solvents. Figure 1 shows DSC thermogram of BSIT. The BSIT sample recrystallized from dioxane-water mixture solvent (named BSIT-I) showed two endothermic peaks at $90^{\circ} \mathrm{C}$ and $220^{\circ} \mathrm{C}$ and the heats of fusion were $14.9 \mathrm{kcal} \mathrm{mol}^{-1}$ and $15.5 \mathrm{kcal} \mathrm{mol}^{-1}$, respectively. The annealed BSIT sample at $100^{\circ} \mathrm{C}$ (BSIT-II) showed only one endotherm at $220^{\circ} \mathrm{C}$ (the heat of fusion was $\left.15.3 \mathrm{kcal} \mathrm{mol}^{-1}\right)$ and annealed BSIT at $250^{\circ} \mathrm{C}$ (BSIT-III) showed so small endothermic peaks at $220^{\circ} \mathrm{C}$ suggested to become a glassy state. BSIT recrystallized from dioxane also showed two endothermic peaks at $91^{\circ} \mathrm{C}$ and $220^{\circ} \mathrm{C}$, but the heat of fusion at $91^{\circ} \mathrm{C}$ was small $\left(7.92 \mathrm{kcal} \mathrm{mol}^{-1}\right)$, because of the formation of rather imperfect crystallites of long alkyl chains.

Both IR spectra of BSIT-I and II showed absorptions at 3300 and $1660 \mathrm{~cm}^{-1}$ (amide structure), at 2850 and $2930 \mathrm{~cm}^{-1}$ (methylene groups), at 1540,1410 and $818 \mathrm{~cm}^{-1}$ (triazine ring), and at $940 \mathrm{~cm}^{-1}$ (isopropenyl group). In the IR spectrum of II type, absorption corresponding to the amide structure appeared at $3430 \mathrm{~cm}^{-1}$, but absorption at 1630 and $1500 \mathrm{~cm}^{-1}$ became very week compared with I type. Figure 2 shows the X-ray diffractogram of BSIT-I and II. BSIT-I showed diffraction at about $2 \theta=25^{\circ}$, indicating $4.2 \AA$ spacing which

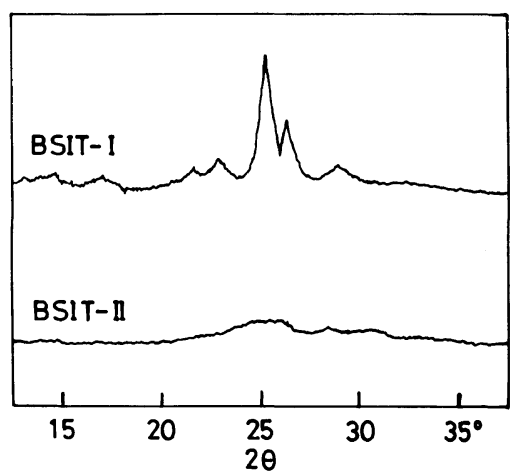

Figure 2. X-Ray diffractograms of BSIT-I and BSIT-II measured by the powder method with $\mathrm{Co}-\mathrm{K}_{\alpha 1}$ radiation. 
is characteristic of hexagonal packing of long alkyl chains. ${ }^{1}$ This diffraction pattern disappeared in BSIT-II. These results suggest that the fusion at $90^{\circ} \mathrm{C}$ of BSIT-I is based on the melting of side-chain crystallites and the fusion at $220^{\circ} \mathrm{C}$, the melting of crystallites concerning amide or triazine structure. In other words, BSIT-II is a mesophase like a liquid crystalline.

\section{Polymerization}

Polymerization was carried out by the usual method $^{12-17}$ using DMA as solvent with azobisisobutyronitrile (AIBN) as an initiator. In the case of copolymerization, methyl methacrylate (MMA) and styrene (St) $\left(\mathrm{M}_{1}\right)$ were used as comonomers. The polymerization tube was degassed and the reaction was allowed to proceed for a prescribed time period at $60^{\circ} \mathrm{C}$. The polymers were precipitated in methanolTHF (10:1) mixture solvent, filtered, dried in vacuo, and weighed. The compositions of the copolymers were calculated by the analytical values of carbon and nitrogen.

The results are shown in Table I. Poly(BSIT) was soluble in THF, $m$-cresol and pyridine. The monomer reactivity ratios were obtained by the Fineman-Ross method. The copolymerization parameters are listed in Table II. Figure 3 shows the monomer-copolymer composition curves for the copolymerization of BSIT $\left(\mathrm{M}_{2}\right)$

Table I. Polymerization of BSIT $\left(\mathrm{M}_{2}\right)$ with St and MMA

\begin{tabular}{|c|c|c|c|c|c|c|c|}
\hline \multirow{3}{*}{$\mathrm{M}_{1}$} & \multicolumn{3}{|c|}{ Conditions $^{\mathbf{a}}$} & \multirow{3}{*}{$\begin{array}{c}\text { Conv. } \\
\quad \%\end{array}$} & \multicolumn{3}{|c|}{ Polymers } \\
\hline & \multirow{2}{*}{$\begin{array}{c}{\left[\mathrm{M}_{2}\right]} \\
\text { in monomer }\end{array}$} & \multirow{2}{*}{$\frac{[\mathrm{M}]_{1}+[\mathrm{M}]_{2}}{\mathrm{~mol} \mathrm{l}^{-1}}$} & \multirow{2}{*}{$\frac{\text { Time }}{\min }$} & & \multirow{2}{*}{$\begin{array}{c}{[\mathrm{M}]_{2}{ }^{\mathrm{b}}} \\
\text { in copolymer }\end{array}$} & \multirow{2}{*}{$\frac{\eta_{\mathrm{sp}} / C^{\mathrm{c}}}{\mathrm{dl} \mathrm{g}^{-1}}$} & \multirow{2}{*}{$\frac{T_{\mathrm{g}}^{\mathrm{d}}}{{ }^{\circ} \mathrm{C}}$} \\
\hline & & & & & & & \\
\hline None & $1.00^{\mathrm{c}}$ & 0.22 & 1440 & 4.4 & 1.00 & 0.27 & - \\
\hline \multirow[t]{12}{*}{ MMA } & 0.957 & 0.18 & 1680 & 4.8 & 0.803 & - & 130 \\
\hline & 0.917 & 0.18 & 1530 & 6.3 & 0.756 & 0.77 & 128 \\
\hline & 0.877 & 0.18 & 1500 & 14.7 & 0.721 & 0.91 & - \\
\hline & 0.797 & 0.17 & 1200 & 26.0 & 0.577 & 0.88 & 124 \\
\hline & 0.733 & 0.23 & 145 & 8.2 & 0.537 & 0.71 & 125 \\
\hline & 0.578 & 0.24 & 150 & 10.3 & 0.499 & 0.89 & 117 \\
\hline & 0.462 & 0.25 & 155 & 9.6 & 0.394 & - & - \\
\hline & 0.354 & 0.26 & 158 & 5.1 & 0.376 & 0.81 & 115 \\
\hline & 0.255 & 0.27 & 130 & 4.8 & 0.306 & 0.69 & 113 \\
\hline & 0.146 & 0.28 & 125 & 2.8 & 0.209 & 0.63 & 105 \\
\hline & 0.099 & 0.70 & 300 & 52.4 & 0.161 & - & 116 \\
\hline & 0.064 & 0.29 & 120 & 1.1 & 0.088 & 0.49 & 101 \\
\hline \multirow[t]{10}{*}{ St } & 0.950 & 0.18 & 1680 & 11.6 & 0.887 & 0.30 & - \\
\hline & 0.923 & 0.18 & 1560 & 12.2 & 0.824 & 0.26 & 128 \\
\hline & 0.848 & 0.22 & 160 & 3.8 & 0.757 & 0.24 & - \\
\hline & 0.691 & 0.24 & 164 & 3.9 & 0.626 & 0.31 & 123 \\
\hline & 0.528 & 0.26 & 210 & 4.8 & 0.529 & 0.31 & 115 \\
\hline & 0.411 & 0.28 & 285 & 6.2 & 0.449 & 0.30 & 114 \\
\hline & 0.309 & 0.30 & 465 & 6.9 & 0.411 & 0.25 & 111 \\
\hline & 0.219 & 0.32 & 1150 & 16.9 & 0.328 & 0.25 & 108 \\
\hline & 0.123 & 0.34 & 1175 & 8.0 & 0.233 & - & 98 \\
\hline & 0.053 & 0.36 & 1175 & 3.1 & 0.138 & - & - \\
\hline
\end{tabular}

a Polymerized at $60^{\circ} \mathrm{C}$ in DMA, [AIBN] $=1.2-1.4 \mathrm{mmol}^{-1}$.

b Determined by $\mathrm{C} \%$ and $\mathrm{N} \%$.

c Measured at $C=0.2 \mathrm{~g} \mathrm{dl}^{-1}$ at $30^{\circ} \mathrm{C}$ in THF.

${ }^{d}$ Measured by DSC at a heating rate of $20^{\circ} \mathrm{C} \mathrm{min}^{-1}$.

e Homopolymerization of BSIT. 
Table II. Copolymerzation parameters of BSIT

\begin{tabular}{clcccrc}
\hline $\mathrm{M}_{2}$ & $\mathrm{M}_{1}$ & $r_{1}$ & $r_{2}$ & $Q_{2}$ & $e_{2}$ & $1 / r_{1}$ \\
\hline \multirow{2}{*}{ BSIT } & MMA & 0.49 & 0.22 & 0.92 & -0.83 & 2.0 \\
& St & 0.35 & 0.44 & 0.96 & 0.57 & 2.9 \\
BHIT $^{\mathrm{a}}$ & MMA & 0.55 & 0.26 & 0.77 & -0.99 & 1.8 \\
& St & 0.51 & 0.60 & 0.82 & 0.29 & 2.0 \\
DAIT $^{\mathrm{b}}$ & MMA & 0.28 & 0.56 & 1.56 & -0.91 & 3.6 \\
& St & 0.28 & 0.99 & 1.45 & 0.33 & 3.6
\end{tabular}

a 2,4 -Bis ( $p$-aminoanilino)-6-isopropenyl-1,3,5-triazine. ${ }^{17}$

b 2,4-Dianilino-6-isopropenyl-1,3,5-triazine. ${ }^{18}$

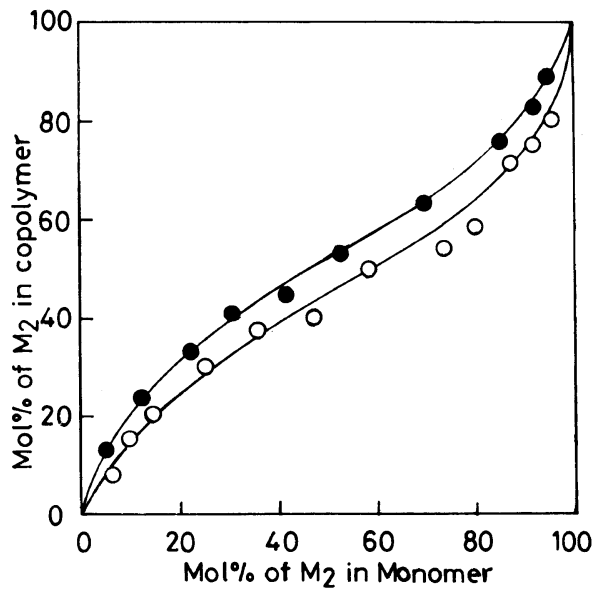

Figure 3. Monomer-copolymer composition curves for the copolymerization of BSIT $\left(\mathrm{M}_{2}\right)$ with styrene $(\mathbf{O})$ and methyl methacrylate $(O)$.

with St and MMA. The plots fit the curves calculated from the monomer reactivity ratios. The $Q$ and $e$ values of BSIT were also calculated in terms of Alfrey-Price's equation based on $Q=1.0$ and $e=-0.8$ for St, and $Q=0.74$ and $e=0.4$ for MMA. The results are also shown in Table II. The copolymerization parameters of BSIT are similar to BHIT without acyl group rather than those of DAIT. ${ }^{18}$ The $e$ values depend on comonomers, that is, positive for copolymerization with $\mathrm{St}$ and negative for MMA. This is general behavior for the copolymerization of isopropenyl-1,3,5-triazine as described previously. ${ }^{12-18}$

\section{Glass Transition Temperature}

The glass transition temperatures $\left(T_{\mathrm{g}}\right)$ of

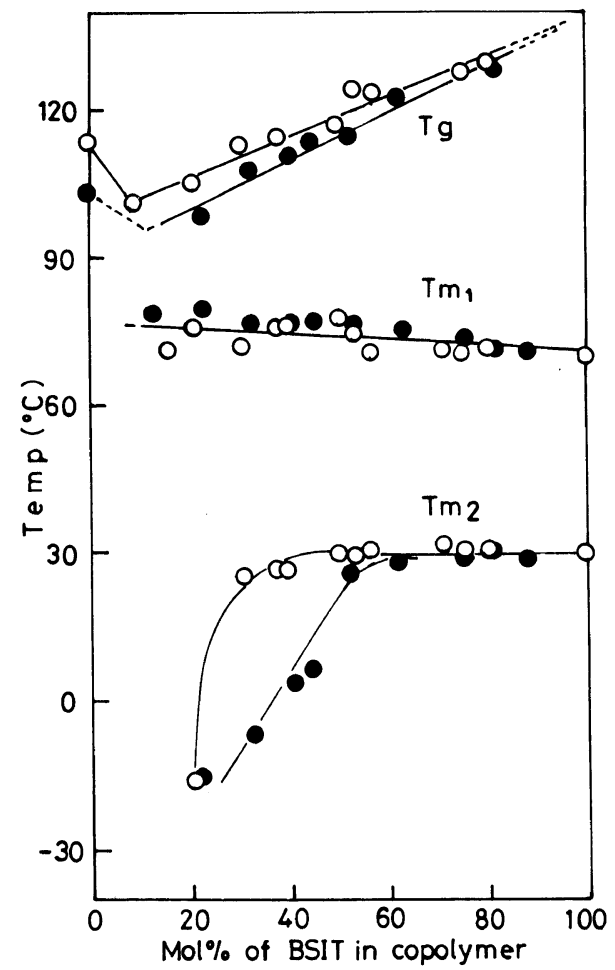

Figure 4. Relationship between glass transition temperatures $\left(T_{\mathrm{g}}\right)$ or melting temperatures of side-chain crystallites on the first heating $\left(T_{\mathrm{m} 1}\right)$ and the second heating $\left(T_{\mathrm{m} 2}\right)$, and BSIT content in copolymers with styrene (O) and methyl methacrylate $(O)$.

copolymers were determined by DSC measurement at the heating rate of $20^{\circ} \mathrm{C} \mathrm{min}^{-1} . T_{\mathrm{g}}$ of poly(BSIT) could not be detected. The results are shown in Table I. Figure 4 shows relations between the $T_{\mathrm{g}}$ and copolymer composition. $T_{\mathrm{g}} \mathrm{s}$ of copolymers showed a minimum at around $10 \%$ molar content of BSIT, and then increased almost linearly with increasing content of BSIT in copolymers. This would be due to internal plasticization caused by the introduction of a small amount of a long alkyl side-chain.

\section{Measurements}

Differential scanning calorimetry (DSC) was determined on a Rigaku-Denki Thermoflex equipped with a low temperature unit. Transition temperatures were evaluated at the 
peak top of DSC curves, and the heat of transition $\Delta H$ (the heat of fusion $\Delta H_{\mathrm{m}}$, and the heat of crystallization $\Delta H_{\mathrm{cr}}$ ) of side-chains per mole of triazine in copolymer was calculated by the following equation based on the heat of transition $\Delta H^{\prime}$ per gram polymer obtained peak area.

$$
\begin{aligned}
& \Delta H\left(\mathrm{kcal} / M_{2} \text { unit mol }\right) \\
& \quad=\Delta H^{\prime}\left(M_{2}+M_{1}\left(1-\mathrm{d} m_{2}\right) / \mathrm{d} m_{2}\right)
\end{aligned}
$$

where $M_{1}$ and $M_{2}$ are molecular weights of monomers and $\mathrm{d} m_{2}$ is BSIT molar content in copolymer.

The X-ray diffractogram was recorded with a powder sample using Co-K $\mathrm{K}_{\alpha 1}(\lambda=1.7889 \AA)$ radiation on a Rigaku-Denki diffractometer.

\section{DISCUSSION}

The crystallization behavior of long alkyl side-chains for resulting comb-like polymers was investigated by DSC measurements and an X-ray diffractogram. Figure 5 shows the DSC thermograms measured at various scanning rate using poly(BSIT-co-St) (BSIT content; $82.4 \mathrm{~mol} \%$ ) as a typical example. The sample was first quenched from room temperature to $-100^{\circ} \mathrm{C}$ and heated to $110^{\circ} \mathrm{C}$ (the first heating) at a scanning rate of $10^{\circ} \mathrm{C} \mathrm{min}{ }^{-1}$, the cooled to $-100^{\circ} \mathrm{C}$ and again heated to $110^{\circ} \mathrm{C}$ at a scanning rate of $20^{\circ} \mathrm{C} \mathrm{min}^{-1}$. The cooling and heating processes (the second heating) were repeated at various scanning rates. An endothermic peak in the heating process and an exothermic peak in the cooling process were observed in the range of about around $0^{\circ} \mathrm{C}$ to $50^{\circ} \mathrm{C}$, except for the first heating. The heat of crystallization $\Delta H_{\mathrm{cr}}$ and heat of fusion $\Delta H_{\mathrm{m} 2}$ were estimated from the DSC peak areas. The relation of these values and scanning rates was listed in Table III. $\Delta H_{\mathrm{cr}}$ and $\Delta H_{\mathrm{m} 2}$ were independent of the scanning rate, and the mean values of $\Delta H_{\mathrm{cr}}$ and $\Delta H_{\mathrm{m} 2}$ were almost equal, $4.8 \mathrm{cal} \mathrm{g}^{-1}$. On the other hand, the melting temperature $\left(T_{\mathrm{m} 1}\right)$ was $72^{\circ} \mathrm{C}$ and heat of fusion
$\left(\Delta H_{\mathrm{m} 1}\right)$ was $6.9 \mathrm{cal} \mathrm{g}^{-1}$ on the first heating. In the case of conventional comb-like polymers, not only $\Delta H_{\mathrm{m}}$ but also $T_{\mathrm{m}}$ of the first and second heatings are similar. ${ }^{19,20}$ The difference of both of $\Delta H_{\mathrm{m}}$ and $T_{\mathrm{m}}$ on the first heating and second heating in this study is believed due to the glassy state of main chain preventing the side-chain crystallization, and side-chain crystallization depending on its thermal history.



Figure 5. DSC thermograms of poly(BSIT-co-St) (BSIT content, $82.4 \mathrm{~mol} \%$ ) at various scanning rates from $-100^{\circ} \mathrm{C}$ to $110^{\circ} \mathrm{C}$. Cooling and heating rates were a, $10^{\circ} \mathrm{C} \min ^{-1}$; b, $20^{\circ} \mathrm{C} \mathrm{min}^{-1}$; c, $10^{\circ} \mathrm{Cmin}^{-1} ; \mathrm{d}, 5^{\circ} \mathrm{C}_{\min ^{-1}}$, and e, $2.5^{\circ} \mathrm{C} \mathrm{min}^{-1}$.

Table III. Relation of side-chain crystallization of poly(BSIT-co-MMA) (BSIT content; $82.4 \mathrm{~mol} \%$ )

\begin{tabular}{|c|c|c|c|c|}
\hline Scanning rate & \multicolumn{2}{|c|}{$-\Delta H_{\mathrm{cr}}^{\prime} \Delta H_{\mathrm{m} 2}^{\prime}$} & $-\Delta H_{\mathrm{cr}}$ & $\Delta H_{\mathrm{m} 2}$ \\
\hline${ }^{\circ} \mathrm{C} \min ^{-1}$ & \multicolumn{2}{|c|}{$\mathrm{calg}^{-1}$} & \multicolumn{2}{|c|}{$\begin{array}{c}\text { kcal } \\
(\text { BSIT-unit mol) }\end{array}$} \\
\hline 20 & 4.69 & 4.48 & 4.16 & 3.98 \\
\hline 10 & 4.88 & 4.87 & 4.33 & 4.32 \\
\hline 5 & 4.70 & 4.83 & 4.17 & 4.29 \\
\hline 2.5 & 4.75 & 4.89 & 4.22 & 4.34 \\
\hline Average value & 4.76 & 4.77 & 4.23 & 4.23 \\
\hline
\end{tabular}
and scanning rate in DSC measurement 
Table IV. Side-chain crystallization of polymers obtained from BSIT

\begin{tabular}{|c|c|c|c|c|c|c|c|c|c|c|}
\hline Polymers & \multirow{3}{*}{$\left(\mathrm{M}_{2} \mathrm{~mol} \%\right)$} & $T_{\mathrm{m} 1}$ & $T_{\mathrm{cr}}$ & $T_{\mathrm{m} 2}$ & $\Delta H_{\mathrm{m} 1}$ & $-\Delta H_{\mathrm{cr}}$ & $\Delta H_{\mathrm{m} 2}$ & $\Delta S_{\mathrm{m} 2}$ & $N_{\mathrm{m} 1}$ & $N_{\mathrm{m} 2}$ \\
\hline \multirow{2}{*}{$\operatorname{Poly}\left(\mathrm{M}_{2}-\mathrm{co}-\mathrm{M}_{1}\right)$} & & \multirow{2}{*}{\multicolumn{3}{|c|}{${ }^{\circ} \mathrm{C}$}} & \multicolumn{3}{|c|}{ kcal } & cal & & \\
\hline & & & & & \multicolumn{3}{|c|}{ BSIT-unit mol } & $\mathrm{deg} \cdot \mathrm{mol}$ & & \\
\hline PolyBSIT & 100 & 70 & 25 & 32 & 7.03 & 5.20 & 4.46 & 14.6 & 4.8 & 3.0 \\
\hline \multirow[t]{12}{*}{ Poly(BSIT-co-MMA) } & 80.3 & 72 & 25 & 31 & 6.52 & 6.03 & 5.87 & 19.3 & 4.4 & 4.0 \\
\hline & 75.6 & 71 & 25 & 31 & 5.98 & 5.51 & 4.94 & 16.3 & 4.1 & 3.4 \\
\hline & 72.1 & 72 & 26 & 32 & 5.96 & 5.07 & 4.95 & 16.2 & 4.1 & 3.4 \\
\hline & 57.7 & 71 & 25 & 31 & 5.97 & 4.02 & 3.88 & 12.8 & 4.1 & 2.6 \\
\hline & 53.7 & 75 & 26 & 30 & 5.38 & 3.48 & 2.64 & 8.7 & 3.7 & 1.8 \\
\hline & 49.9 & 78 & 25 & 30 & 5.35 & 3.35 & 2.36 & 7.8 & 3.6 & 1.6 \\
\hline & 39.4 & 77 & 25 & 27 & 5.45 & 2.97 & 2.19 & 7.3 & 3.7 & 1.5 \\
\hline & 37.6 & 76 & 23 & 27 & 5.48 & 1.94 & 2.11 & 7.0 & 3.7 & 1.4 \\
\hline & 30.6 & 72 & 14 & 26 & 4.65 & 1.50 & 1.66 & 5.6 & 3.2 & 1.1 \\
\hline & 20.9 & 76 & -23 & -16 & 4.73 & 1.28 & 1.44 & 5.6 & 3.2 & 1.0 \\
\hline & 16.1 & 71 & - & - & 4.40 & - & - & - & 3.0 & - \\
\hline & 8.8 & -26 & - & - & 1.12 & - & - & - & 0.8 & - \\
\hline \multirow[t]{10}{*}{ Poly(BSIT-co-St) } & 88.7 & 71 & 22 & 29 & 6.02 & 5.27 & 5.22 & 17.3 & 4.1 & 3.6 \\
\hline & 82.4 & 72 & 25 & 30 & 6.10 & 4.50 & 4.04 & 13.3 & 4.1 & 2.7 \\
\hline & 75.7 & 74 & 24 & 29 & 6.34 & 4.17 & 3.43 & 11.4 & 4.3 & 2.3 \\
\hline & 62.6 & 76 & 23 & 28 & 5.62 & 3.11 & 2.50 & 8.3 & 3.8 & 1.7 \\
\hline & 52.9 & 77 & 23 & 26 & 5.67 & 2.73 & 2.45 & 8.2 & 3.9 & 1.7 \\
\hline & 44.9 & 78 & 12 & 14 & 5.99 & 2.95 & 2.27 & 8.1 & 4.1 & 1.5 \\
\hline & 41.1 & 77 & 8 & 10 & 6.71 & 2.67 & 2.36 & 8.5 & 4.6 & 1.6 \\
\hline & 32.8 & 77 & -7 & -5 & 6.93 & 2.20 & 1.80 & 6.8 & 4.7 & 1.2 \\
\hline & 23.3 & 80 & -26 & -16 & 6.34 & 1.38 & 1.45 & 5.6 & 4.3 & 1.0 \\
\hline & 13.8 & 79 & - & - & 6.52 & - & - & - & 4.4 & - \\
\hline
\end{tabular}

In order to evaluate side-chain crystallization, the other polymer samples were subjected to DSC measurement from $-100^{\circ} \mathrm{C}$ to $110^{\circ} \mathrm{C}$ at a scanning rate of $10^{\circ} \mathrm{C} \mathrm{min}^{-1}$. DSC curves of poly(BSIT) and copolymers exhibited the same tendency as described above. The thermal parameters, that is, the melting temperature $T_{\mathrm{m} 1}$ and heat of fusion $\Delta H_{\mathrm{m} 1}$ on the first heating, crystallization temperature $T_{\mathrm{cr}}$ and the heat of crystallization $\Delta H_{\mathrm{cr}}$ on the cooling, and melting temperature $T_{\mathrm{m} 2}$ and the heat of fusion $\Delta H_{\mathrm{m} 2}$ on the second heating are summarized in Table IV. Table IV also shows the entropy of fusion $\Delta S_{\mathrm{m} 2}$ calculated from $\Delta H_{\mathrm{m} 2}$ and $T_{\mathrm{m} 2}$.

Figure 4 shows the relations between $T_{\mathrm{g}}, T_{\mathrm{m} 1}$ or $T_{\mathrm{m} 2}$ and the copolymer composition. Figure 6 shows the relations between $\Delta H_{\mathrm{m} 1}$ or $\Delta H_{\mathrm{m} 2}$ and the copolymer composition. $T_{\mathrm{g}} \mathrm{s}$ of copolymers are higher than their $T_{\mathrm{m} 1} \mathrm{~s}$ and
$T_{\mathrm{m} 2} \mathrm{~s} . T_{\mathrm{m} 1} \mathrm{~s}$ of copolymers were almost constant at around $70-80^{\circ} \mathrm{C}$ independent of the comonomers and their compositions. The melting phenomenon on the first heating means the melting of the crystallites which grew slowly on standing at room temperature after the polymerization. $T_{\mathrm{m} 2} \mathrm{~s}$ and $T_{\mathrm{cr}} \mathrm{s}$ of copolymers are lower than $T_{\mathrm{m} 1} . T_{\mathrm{m} 2} \mathrm{~s}$ were almost constant at around $30^{\circ} \mathrm{C}$ above $40 \%$ BSIT content for MMA and above $50 \%$ for St. $T_{\mathrm{m} 2}$ may be concerned with the rate of the formation and the perfection of crystallites and thus, the lower $T_{\mathrm{m} 2}$ means the slower formation of rather imperfect crystallites. The long alkyl groups of poly(BSIT-co-St) will be miscible with phenyl group of St and the formation of crystallites becomes slower compared to MMA copolymers. On the other hand, $\Delta H_{\mathrm{m} 1} \mathrm{~s}$ for St copolymers were almost constant, but those for 


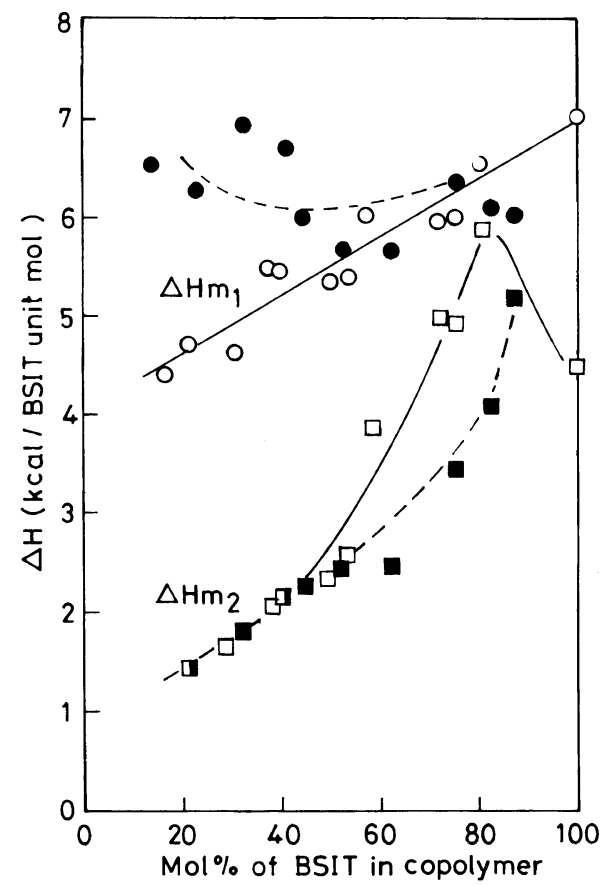

Figure 6. Relationship between heat of fusion of sidechain crystallites on the first heating $\left(\Delta H_{\mathrm{m} 1}\right)$ or the second heating $\left(\Delta H_{\mathrm{m} 2}\right)$ and BSIT content in the copolymers with styrene $(\boldsymbol{O}, \square)$ and methyl methacrylate $(O, \square)$.

MMA copolymers decreased with decreasing the BSIT content. Because $\Delta H_{\mathrm{m} 1}$ is proportional to the quantities of side-chain crystallites, the difference of $\Delta H_{\mathrm{m} 1}$ for both copolymers may be related to the different flexibility of main chain consisting of St or MMA unit. That is, less flexible MMA unit prevents the side-chain crystallization. $\Delta H_{\mathrm{m} 2} \mathrm{~s}$ showed the maximum value at $90 \%$ BSIT content and then decreased with decreasing BSIT contents. This result is ascribed to the fact that small amounts of the comonomer may work as a spacer favorable to the side-chain crystallization.

Further investigation was made for the effect of the thermal history on the side-chain crystallization. Figure 7 shows DSC thermogram of poly(BSIT-co-MMA) (BSIT content; $57.7 \mathrm{~mol} \%$ ) heated above its $T_{\mathrm{g}}$. After annealing at $150^{\circ} \mathrm{C}$ for $2 \mathrm{~h}, \Delta H_{\mathrm{m} 2}$ became similar to that on the first heating, but $T_{\mathrm{m} 2}$ was $30^{\circ} \mathrm{C}$.

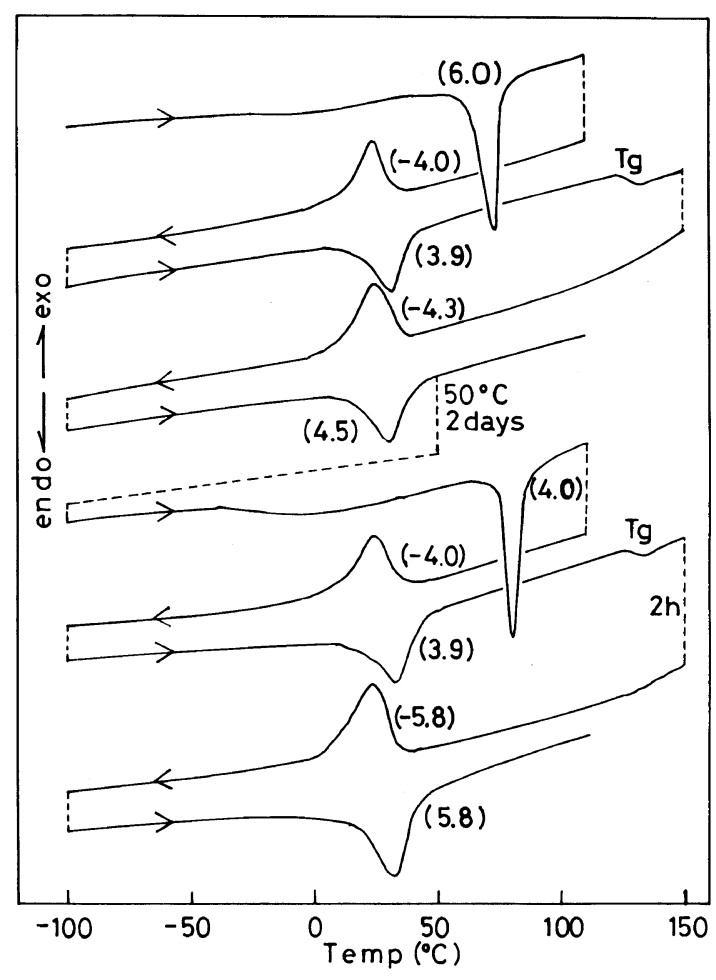

Figure 7. DSC thermograms of poly(BSIT-co-MMA) (BSIT content, $57.7 \mathrm{~mol} \%$ ) at heating and cooling rate of $10^{\circ} \mathrm{C} \mathrm{m^{-1 }}$. Numbers in parentheses mean values of heats of fusion or heats of crystallization in kcal (BSIT unit $\mathrm{mol})^{-1}$.

The sample annealed at $50^{\circ} \mathrm{C}$ for 2 days melted at $70^{\circ} \mathrm{C}$. These shows that the growth of side-chain crystallites under $T_{\mathrm{g}}$ of main-chain is slow and side-chain crystallization has many complicated factors, especially including annealing time and temperature.

$\mathrm{X}$-ray diffraction patterns of polymers are shown in Figure 8. The polymers with high content of BSIT showed only a diffraction peak at $2 \theta=24.8^{\circ}$ (a spacing of $4.2 \AA$ ), corresponds to the hexagonal packing as reported for conventional comb-like polymer. ${ }^{1,21}$ The copolymers with low content of BSIT showed two reflection peaks at $23.6^{\circ}$ (a spacing of $4.4 \AA$ ) and $24.8^{\circ}$. Crystallites having $4.2 \AA$ or $4.4 \AA$ were tight and loose crystallites, respectively. In DSC measurements, only one melting endotherm at $70^{\circ} \mathrm{C}$ was observed for both 


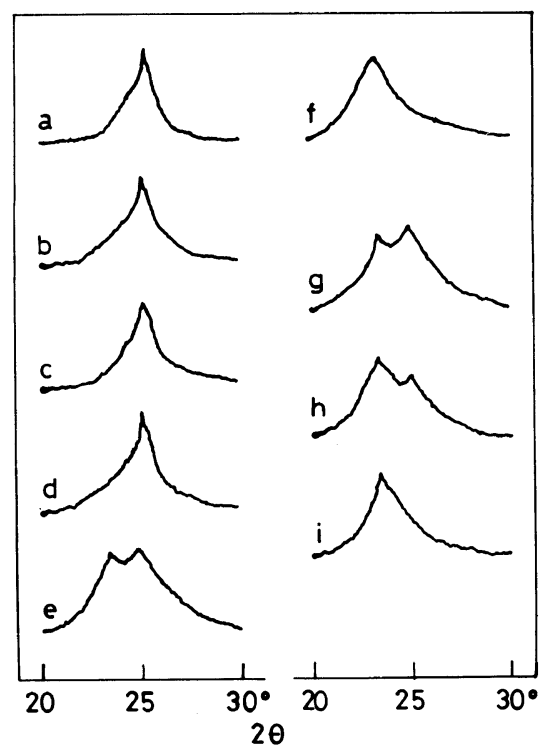

Figure 8. X-Ray diffractgrams of poly(BSIT) and copolymers measured by the powder method with $\mathrm{Co}-\mathrm{K}_{\alpha 1}$ radiation. a, poly(BSIT); b, poly(BSIT-co-St), BSIT, $88.7 \mathrm{~mol} \%$; c, poly(BSIT-co-St), BSIT, $75.7 \mathrm{~mol} \%$; d, poly(BSIT-co-MMA), BSIT, $57.7 \mathrm{~mol} \%$; e, poly(BSIT-coMMA), BSIT, $20.9 \mathrm{~mol} \%$; f, poly(BSIT-co-MMA), BSIT, $16.1 \mathrm{~mol} \%$; g, poly(BSIT-co-St), BSIT, $32.8 \mathrm{~mol} \%$; h, poly(BSIT-co-St), BSIT, $32.8 \mathrm{~mol} \%$ annealed at $50^{\circ} \mathrm{C}$ for 3 days; i, poly(BSIT) annealed at $90^{\circ} \mathrm{C}$ for $1 \mathrm{~h}$.

copolymers showing different X-ray diffractogram. The tight and loose crystallites may be closely related because of the same melting temperature; that is, they form thermodynamically one crystalline. On the other hand, the poly(BSIT) annealed at $90^{\circ} \mathrm{C}$ showed only a reflection at $23.6^{\circ}$, which melted at around $30^{\circ} \mathrm{C}$. It is considered about side-chain crystallization under $T_{\mathrm{g}}$ that first, loose crystallites are formed and melt at around $30^{\circ} \mathrm{C}$. The loose crystallites slowly change to tight crystallites, which melt at $70^{\circ} \mathrm{C}$. On the other hand, new loose crystallites grow near tight crystallites, and melt with old tight crystallites at $70^{\circ} \mathrm{C}$. This relation is shown in Scheme 1 .

In general, the numbers of crystallizing $\mathrm{CH}_{2}$ groups $(N)$ in a side-chain are calculated from $\Delta H_{\mathrm{m}}$ on the basis of the heat of fusion per $\mathrm{CH}_{2}$ of $n$-alkanes in the hexagonal packing

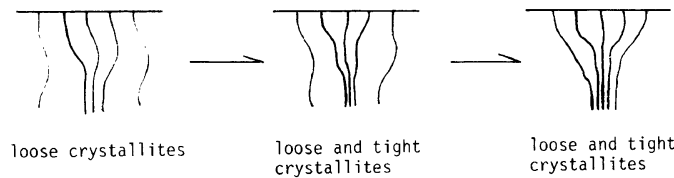

Scheme 1.

(735 cal mol ${ }^{-1} \mathrm{CH}_{2}{ }^{-1}$ ). ${ }^{22}$ The $N$ numbers of the present polymers are shown in Table IV. Ns of poly(octadecyl methacrylate) ${ }^{8}$ and poly(A18IT) having an octadecanoyl group were 5.6 and 2.1 , respectively. The resulting polymers in this work gave similar $N$ values to those of the conventional comb-like polymers. $T_{\mathrm{g}} \mathrm{s}$ of the conventional comb-like polymers were lower than the melting points of the side-chain crystallites. Therefore, the mainchains of the conventional comb-like polymers may be flexible enough to allow the side-chain packing. However, $T_{\mathrm{g}} \mathrm{s}$ of the present polymers were higher than the melting point of the sidechain crystallites. Consequently, the effects of the less flexible main-chain and two long acyl groups of present polymers were compensated for the formation of side-chain crystallites.

\section{REFERENCES}

1. N. A. Platé and V. P. Shibaev, J. Polym. Sci. Macromol. Rev., 8, 117 (1974).

2. E. F. Jordan, Jr., G. R. Riser, B. Artymyshyn, W. E. Parker, and J. W. Pensabene, J. Appl. Polm. Sci., 13, 1777 (1969).

3. E. F. Jordan, Jr., G. R. Riser, B. Artymyshyn, J. W. Pensabene, and A. N. Wrigley, J. Polym. Sci., A-2, 10, 1657 (1972).

4. S. M. Aharoni, Macromolecules, 12, 94 (1979).

5. M. Takayanagi and T. Katayose, J. Appl. Polym. Sic., 29, 141 (1984).

6. J. Watanabe, H. Ono, I. Uematsu, and A. Abe, Macromolecules, 18, 2141 (1985).

7. T. Miyashita, H. Yoshida, T. Murakata, and M. Matsuda, Polymer, 28, 311 (1987).

8. K. Yokota, T. Kougo, and T. Hirabayashi, Polym. J., 15, 891 (1983).

9. S. S. Rogers and L. Mandelkern, J. Phys. Chem., 61, 985 (1957).

10. J. W. Mays, E. Siakali-Kioulafa, and N. Hadjichristidis, Macromolecules, 23, 3530 (1990).

11. S. A. Greenberg and T. Alfrey, J. Am. Chem. Soc., 
76, 6280 (1954).

12. Y. Yuki, H. Musika, and T. Kito, Kobunshi Ronbunshu, 36, 385 (1979).

13. H. Kunisada, Y. Yuki, T. Ochiai, M. Nishii, and S. Sano, Kobunshi Ronbunshu, 45, 911 (1988).

14. H. Kunisada, Y. Yuki, Y. Matsushita, M. Inuzuka, M. Yamazaki, and T. Yoshida, Kobunshi Ronbunshu, 47, 33 (1990).

15. H. Kunisada, Y. Yuki, Y. Miyake, A. Ogawa, and H. Yoshimura, Polym. J., 23, 29 (1991).

16. H. Kunisada, Y. Yuki, S. Kondo, J. Miyatake, and C. Maeda, Polym. J., 22, 559 (1990).
17. Y. Yuki, H. Kunisada, and S. Kondo , Kobunshi Ronbunshu, 46, 233 (1989).

18. Y. Yuki, H. Kunisada, J. Taniuchi, and N. Takizuka, Nippon Kagaku Kaishi, 224 (1987).

19. T. Hirabayashi, T. Kikuta, K. Kasabo, and K. Yokota, Polym. J., 20, 693 (1988).

20. T. Hirabayashi, K. Kasabo, and K. Yokota, Polym. J., 20, 911 (1988).

21. B. Espenschied and R. C. Schulz, Makromol. Chem., Rapid Commun., 4, 633 (1983).

22. M. G. Broadhurst, J. Res. Natl. Bur. Stand., 66A, 241 (1962). 